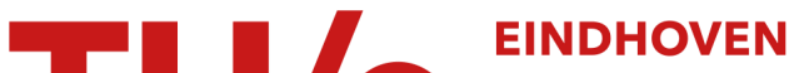 UNIVERSITY OF TECHNOLOGY
}

\section{On occupant-centric building performance metrics}

\section{Citation for published version (APA):}

O'Brien, W., Gaetani, I., Carlucci, S., Hoes, P., \& Hensen, J. L. M. (2017). On occupant-centric building performance metrics. Building and Environment, 122, 373-385. https://doi.org/10.1016/j.buildenv.2017.06.028

\section{Document license:}

TAVERNE

DOI:

10.1016/j.buildenv.2017.06.028

\section{Document status and date:}

Published: 01/09/2017

\section{Document Version:}

Publisher's PDF, also known as Version of Record (includes final page, issue and volume numbers)

\section{Please check the document version of this publication:}

-A submitted manuscript is the version of the article upon submission and before peer-review. There can be important differences between the submitted version and the official published version of record. People interested in the research are advised to contact the author for the final version of the publication, or visit the $\mathrm{DOI}$ to the publisher's website.

- The final author version and the galley proof are versions of the publication after peer review.

- The final published version features the final layout of the paper including the volume, issue and page numbers.

Link to publication

\section{General rights}

Copyright and moral rights for the publications made accessible in the public portal are retained by the authors and/or other copyright owners and it is a condition of accessing publications that users recognise and abide by the legal requirements associated with these rights.

- Users may download and print one copy of any publication from the public portal for the purpose of private study or research.

- You may not further distribute the material or use it for any profit-making activity or commercial gain

- You may freely distribute the URL identifying the publication in the public portal.

If the publication is distributed under the terms of Article $25 \mathrm{fa}$ of the Dutch Copyright Act, indicated by the "Taverne" license above, please follow below link for the End User Agreement:

www.tue.nl/taverne

\section{Take down policy}

If you believe that this document breaches copyright please contact us at:

openaccess@tue.nl

providing details and we will investigate your claim. 


\title{
On occupant-centric building performance metrics
}

\author{
William O'Brien ${ }^{\text {a, }}$, Isabella Gaetani ${ }^{\text {b }}$, Salvatore Carlucci ${ }^{\text {c }}$, Pieter-Jan Hoes ${ }^{\text {b }}$, \\ Jan L.M. Hensen ${ }^{b}$ \\ a Carleton University, Ottawa, Canada \\ b Eindhoven University of Technology, Netherlands \\ ${ }^{\mathrm{c}}$ Norwegian University of Science and Technology, Trondheim, Norway
}

\section{A R T I C L E I N F O}

\section{Article history:}

Received 20 February 2017

Received in revised form

8 June 2017

Accepted 13 June 2017

Available online 16 June 2017

\section{Keywords:}

Building performance

Occupancy

Occupant behavior

Metrics

Simulation

\begin{abstract}
A B S T R A C T
Existing building performance metrics cover a wide variety of domains including energy performance, equipment performance, electric lighting, indoor environmental quality, capital and operating costs, and environmental impact. They facilitate building benchmarking and yield actionable insights at all phases of the building life-cycle. Yet, the occupant domain - one of the most significant with respect to building performance - is relatively immature with regards to performance metrics. This paper provides guidance, examples, and critical discussion for developing and applying occupant-centric building performance metrics. First, an approach is proposed for developing and evaluating the suitability of such metrics. Then, using samples of data from real and simulated buildings, this paper proposes metrics that are appropriate for quantifying occupants' impact on buildings. These metrics provide an indication of building performance from an occupant-building interaction perspective, serving a purpose much like traditional building performance metrics. They also force professionals to consider occupants through a new lens because people are the real recipient of the measures and services provided by buildings.
\end{abstract}

๑) 2017 Elsevier Ltd. All rights reserved.

\section{Introduction}

The performance of a building, in which people spend the greatest share of their life, is the result of a complex interaction between a large variety of physical attributes. In the literature, an assortment of terminology is used when assessing building performance. Some studies make a distinction between metrics and key performance indicators [1], while others consider these terms synonymous [2]. Other papers focus on the difference between simple metrics (such as the floor area of a building) and performance metrics (such as building energy use intensity, or EUI, defined as the yearly energy demand per unit area of the building, e.g., in $\mathrm{kWh} / \mathrm{m}^{2}$ ) [3]. In this study, we refer to performance metrics as measurement standards of a function or operation, which can measure and communicate progress towards achieving performance goals [3]. A building performance metric is "intended to explicitly represent the performance objectives for a building project, using quantitative criteria, in a dynamic structured format" [4]. Developing significant building performance metrics is a

\footnotetext{
* Corresponding author.

E-mail address: liam_obrien@carleton.ca (W. O'Brien).
}

required step to set appropriate goals in building design, which moved from traditionally being a prescriptive process to be performance-based [5].

Several hundred building performance metrics are available in the scientific literature and are adopted by standards and legislation to set requirements for building performance [6]. Those metrics address various aspects of the building performance [7], including occupant behavior and indoor environmental quality (IEQ). However, an effective and standardized way to quantify key aspects of building performance from an occupant perspective is not sufficiently developed. As a result, there lacks a common approach for the development of occupant-centric (i.e., focused on the occupant-building interaction) performance metrics for use in simulation and/or for assessing the operational performance of buildings. This gap renders it difficult to quantify and define objectives concerning building performance in relation to occupants. Moreover, neglecting this important aspect of building performance can lead to drawing incorrect or inappropriate conclusions about the actual energy consumption of the building stock. The primary objective of the occupant-centric metrics proposed in this paper is not to specifically evaluate individual occupants, but to assess the building through a new lens by gaining a better understanding of how occupants influence building performance. In 
contrast to when the prominent building performance metrics (such as the EUI) were established, new sensing and building automation and control system (BACS) technologies support highresolution occupancy and occupant behavior sensing. For instance, numerous technologies are available to count and even locate occupants within a building. Moreover, modern BACS technologies can detect and log occupant interactions with lighting controls, thermostats, etc. (e.g., [8]). Overall, this research is made possible by the diffusion of BACS and building performance simulation (BPS) tools.

This paper first provides an overview of a few existing performance metrics, with the aim of highlighting the overlapping areas of interest and discussing where the current approach falls short of an objective building performance assessment. Next, an approach for the development of occupant-centric performance metrics is provided. A number of illustrative examples demonstrate the development and application of occupant-centric performance metrics to real data and simulation results. The findings and suggestions for developing occupant-centric building performance metrics and the lessons learned from this exercise are examined and summarized in the last section.

\section{Existing building performance metrics related to occupants}

This section introduces a selection of common existing building performance metrics and provides a critical assessment of their effectiveness in the current context of occupants. Later on in Section 4, metrics that help to address the current metrics' shortcomings, according to the same categories below, are proposed and tested.

\subsection{Energy and comfort performance metrics}

There are many possible ways to characterize a building performance, for example, its structural safety, aesthetic quality, economic value, or environmental impact. In this paper, however, building performance refers to buildings' energy and comfort performance. There is a number of very extensive frameworks for comfort and more in general IEQ assessment [9-11]. Some issues emerge when correlating discomfort metrics to occupants. For example, ASHRAE Standard 90.1 (Appendix G3.1.2.3) [12] requires a baseline building to have less than 300 unmet hours, or "hours of the modeled year in which at least one zone has an unmet cooling/ heating load". However, the fact that there are no specifications concerning actual occupancy of the building nor how to deal with multiple zones is a shortcoming. To correlate the building thermal comfort performance to occupants, Carlucci [13] developed a longterm thermal discomfort index that assesses the whole-building performance by weighting the zonal indices by the number of people that occupy each zone for each hour.

\subsection{Normalization factor}

The role of occupants is largely overlooked when it comes to energy performance metrics. However, an extensive body of work emerged in recent years with concerns to normalization factor. The idea behind these studies is to progress from normalizing energy use per building size, to focusing on the actual service delivered by the building - that is, providing a comfortable and productive environment for people [56]. This approach is common to other fields. For example, it would seem illogical to most car users to normalize cars' fuel consumption by the empty mass of the car in kilograms rather than by kilometers (the actual service provided by the car). When analyzing energy use for travel between 1970 and
1987 [14], found that the energy intensities - expressed in terms of $\mathrm{MJ} /($ passenger $\mathrm{km}$ ) - generally increased in many OECD countries; although individual cars had become more energy-efficient, this improvement was offset by their greater size, power, weight, and load factor (i.e., passengers per car). The authors' findings are representative of the trends over time in terms of car industry environmental sustainability, but they would have been reversed if the performance metric's normalization factor was automobile size or weight.

Examples of building energy use per capita as a performance metric are found when presenting macro trends of the building sector regarding energy (e.g., [2]). The adoption of a similar logic is rarer when it comes to single buildings [15]. found that normalizing life-cycle energy and greenhouse gas (GHG) emissions by floor area revealed that a large suburban house performs nearly as well as an urban transit-accessible apartment. However, normalization by occupant for the same study revealed that the large suburban house was more than twice as energy and GHG-intensive as its urban counterpart. Similarly, Ueno [16] states that normalizing energy per floor area in residential buildings undoubtedly leads to a "small house penalty". The study shows that a dwelling whose area is $269 \mathrm{~m}^{2}$ has an energy performance "advantage" of 30\% over an identical, smaller version $\left(158 \mathrm{~m}^{2}\right)$. From this perspective, the easiest way to reduce a dwelling's EUI would be to finish the basement, and include it in the floor area calculation. This logic clearly does not lead to an improved design of societal and environmental sustainability. On the other hand, normalizing energy by number of occupants leads to a "large house penalty" (which is representative of actual energy use), in addition to the difficulty of measuring and defining the number of occupants. This paper argues that considering how people use and occupy such spaces in reality could provide further insights on the efficiency of the services provided by a building.

\subsection{Trend of increasing space utilization}

Current metrics to evaluate office building utilization are static in nature and typically based on occupant density (on the basis of floor area divided by full-time equivalent employees) with little regard to true occupancy [17]. However, there is a trend of office tenants who are moving to hoteling-style office management, whereby there is only one desk for every two or three office workers to reflect their flexibility to work from home or other sites and be in meetings $[18,19]$. This form of building management has major potential economic and environmental benefits, as less floor area is required to conduct the same level of economic activity and it reduces pressure on commuting infrastructure. For instance, hoteling could allow a building operator to shut down part of a building (e.g., cease conditioning it) or it could allow a growing business to delay expanding into a new building. A similar trend can be seen in colleges and universities, which are beginning to offer online courses whereby physical classrooms are not necessarily needed. Meanwhile, the sharing economy has seen major growth in short-term person-to-person house sharing. All of these trends can greatly improve building utilization and ultimately require less building space for a given population. However, to the best of the authors' knowledge, no current metric gives credit for improved utilization nor quantifies the potential for greater utilization. In the past years, a variety of new technologies that allow detailed occupancy counts at various scales (building, suite, room) to better track space utilization emerged $[20,21]$; this development will be instrumental for the quantification of buildings' intensified utilization potential. 


\subsection{Occupied versus unoccupied energy use}

Considering occupants is imperative when it comes to comparing energy use during occupied and unoccupied hours. Masoso and Grobler [22] found out, by means of detailed energy audits, that $56 \%$ of the total energy used in five African commercial buildings occurred during non-working hours. Harris and Higgins [23] suggested 'Overnight Ratio' as an indicator to quantify the nighttime to daytime plug load power (for which they calculated a median value of 55\%). Webber et al. [24] used field surveys to assess the type and state of plug loads (on, low, off, or unplugged). For their study, the authors spent $4 \mathrm{~h}$ in each of 12 office buildings with an average sample size of 140 computers to assess nighttime equipment state. Such spot checks provide considerable insight, but are labor intensive and may become obsolete as office equipment evolves in energy efficiency and type. In contrast, newer metering and sensing technologies can provide continuous quantification of plug load related metrics.

Other performance metrics could convey more accurate descriptions of buildings' actual performance if the human factor is included. For example, daylight autonomy (DA) represents the fraction of occupied hours during which daylight is adequate to offset electric lights [25]. While this performance metric is a good indicator of the availability of daylight in a space, it does not indicate actual lighting energy use. DA does not recognize the impact of the exact nature of the lighting controls (e.g., manual or vacancycontrolled). Hence, the values expressed by the metric do not necessarily indicate energy performance.

In summary, including occupants in performance metrics could provide a suitable and reliable way to assess a building's actual energy performance. Many common existing metrics that do not explicitly consider occupants lead to significant bias and do not recognize the impact of occupants. Recent studies show the advantages of this approach, and emerging technologies enable turning this concept into practice.

\section{Approach for developing building performance metrics}

Developing meaningful and efficient performance metrics is a difficult task that calls for a methodological guidance. In Section 3.1, the purpose and context of performance metrics is discussed, with a focus on performance metrics' hierarchy and dynamics throughout the building life-cycle. Then, the elements of a good performance metric are presented in Section 3.2.

\subsection{Performance metrics: purpose and context}

As stated before, performance metrics are developed to help in quantifying a performance objective. While clear goals are the starting point of each design process, a set of sub-metrics is often needed to help in specifying, tracking and maintaining the performance objective. This set can be organized hierarchically to facilitate setting measurable, meaningful and actionable goals. The breakdown of a performance objective can be: conceptual, meaning that, to quantify a high-level metric (e.g., building EUI or delivered energy), one must quantify various categories concurring to that metric (e.g., energy need for space heating and cooling, etc.); spatial, when the attention is drawn to the portion of space which is considered (e.g., zone-level energy need, etc.); and/or temporal, at different temporal discretization levels (e.g., hourly energy need, etc.).

The performance objective defines the type of hierarchy resolution which may be needed. For example, if the purpose of the analysis is to assess whether a building's EUI is compliant with building regulations, a high-level hierarchy is sufficient. As the purpose of the simulation and the amount of decided design parameters typically changes during the building life-cycle [26], the required hierarchy resolution is strictly dependent on the stage of the building process. For example, during the planning and initial design phase of a building it is not possible to investigate equipment energy use specifically, as the space use and corresponding equipment may not have been defined yet. On the other hand, information about sub-hourly energy use is needed, for example, to optimize a building operation. Fig. 1 is an example of a possible breakdown of whole building energy use, following conceptual, spatial and temporal hierarchy.

Accordingly, performance metrics are defined, calculated and tracked during the different phases of the building life-cycle [27]. During the planning phase, an initial set of performance metric targets is defined. The set is updated and modified as a result of design interactions during the design phase. Building performance can be assessed with computer-based simulations and other means, and the assessment results become the benchmark of expected performance during operation. Defining and refining the performance metrics during design phase hence ensures both that the initial targets are decomposed into an actionable level, and that there is a benchmark for future assessment. During commissioning, the variables which are to be measured during operation are identified and their expected performance is set. A good metric ideally enables low-effort measurement to compare actual and predicted performance of a building. Measurements are typically obtained at a different time/space resolution as computer simulations, and may need to be converted for direct comparison. The metric data measured following commissioning are the benchmarks for operation optimization, maintenance and retrofit.

Fig. 2 shows how performance metrics are obtained by various means according to the phase of the building life-cycle. Traditionally, some occupant-centric metrics could only be measured in a specific phase of the life-cycle. For example, the electricity use for equipment during non-occupied office hours could be measured during operation phase only. The recent developments in the field of occupant behavior modeling [28] also allow predicting occupant-centric building performance metrics during the design phase, as new modeling formalisms consider occupants with a higher level of detail.

The currently available sensing technologies enable tackling performance optimization during operation, as it is finally possible to measure previously set performance targets. Continuous quantification of performance metrics for design into operation facilitates detection and diagnosis for causes of underperformance, which often goes unnoticed [29]. In order to enable the assessment of a building's performance throughout its life-cycle, it is important that simple methods for monitoring and tracking operating characteristics (e.g., energy end use and occupancy by room) are available.

Ideally, a good performance metric and corresponding target value or range can be: (i) set with the client beforehand (and be the basis for energy performance contracting); (ii) predicted during the various design stages; and, (iii) measured/checked in the real building after completion. However, it is important to note that not all performance metrics are appropriate for each phase in the building life-cycle. Again, their relevance depends on their purpose. For example, some performance metrics could be useful as targets to optimize the design, but are not intended to be tracked during operation. This is typically the case of thermal comfort metrics such as Predicted Mean Vote (PMV) [30], for which two variables (metabolic rate and clothing insulation) must be assumed as they are difficult to collect, depend on the specific person, and are affected by a potentially large variance and uncertainty. 


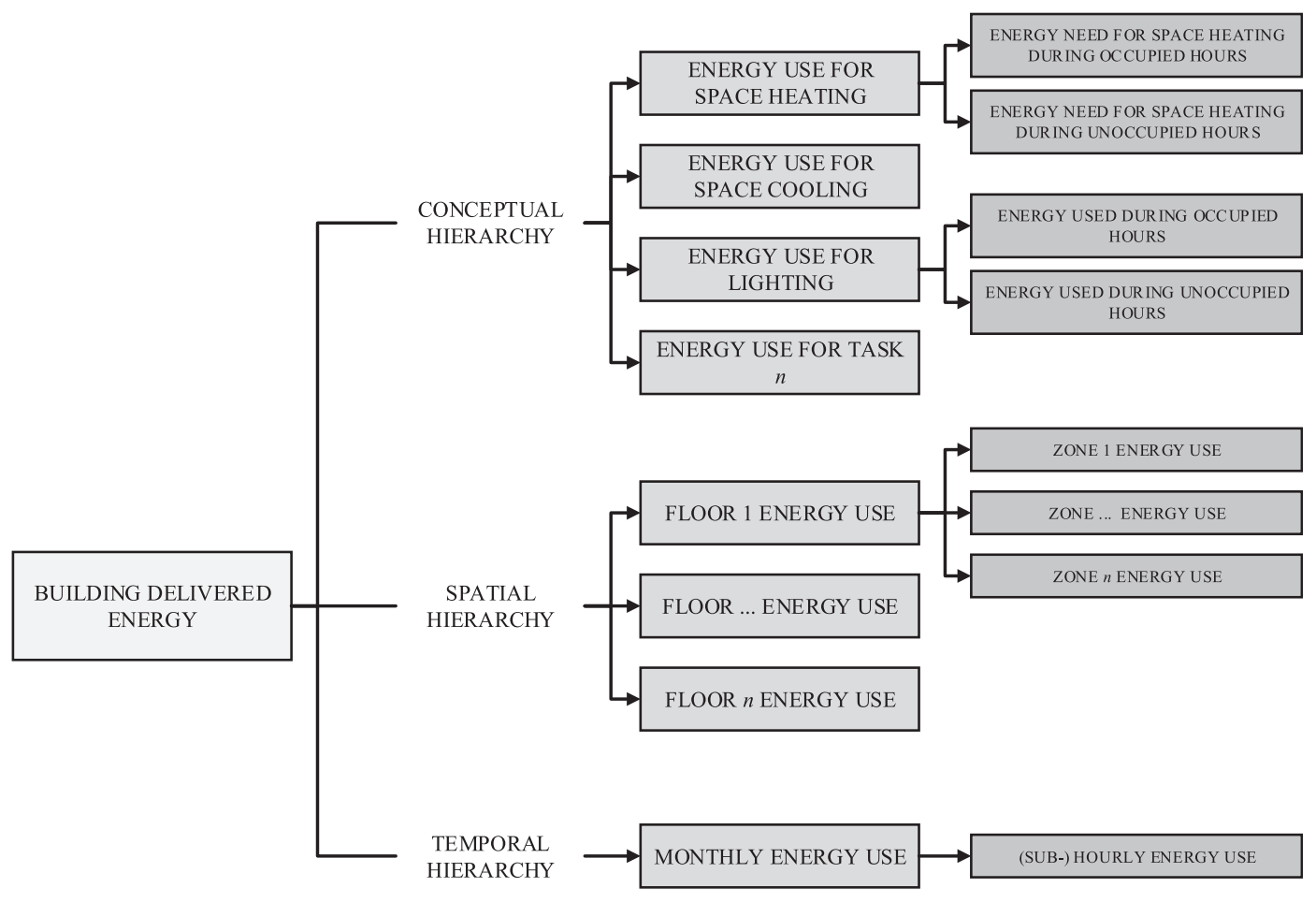

Fig. 1. Hierarchy in building energy performance metrics.

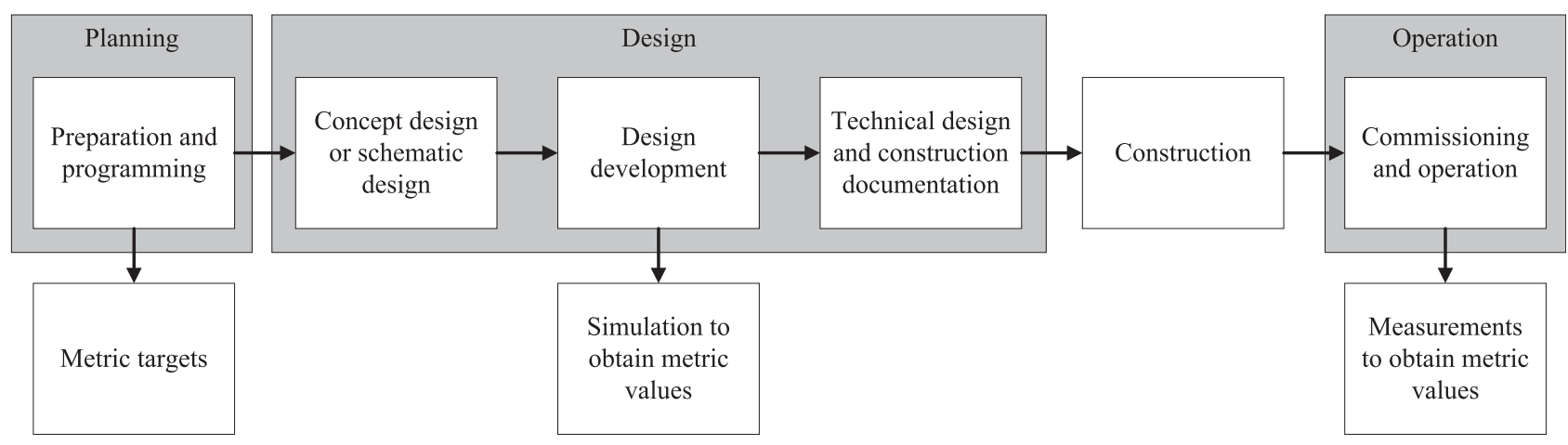

Fig. 2. Dynamics in occupant-centric building performance metrics.

\subsection{What is (and isn't) a good performance metric?}

\subsubsection{Pitfalls and challenges}

When attempting to develop significant performance metrics in the field of building performance, some key challenges ought to be considered.

As Reinhart, Mardaljevic, and Rogers [31] point out, particular attention should be posed to the message conveyed to design practice by performance metrics: the design that satisfies a given performance metric should be better performing than an alternative design that does not satisfy the performance metric's target. It should be to ensured that a metric's interpretation is not exaggerated or biased. For instance, the optimal building design, on the basis of using daylight factor, is a fully glazed building envelope [31]. But this clearly leads to a number of drawbacks regarding energy and comfort performance.

Some performance metrics have no bounds, while others are developed to reach a particular threshold or to be within a certain acceptable range. The advantage to metrics with bounds is that they come with additional context (e.g., minimum/maximum possible value).

\subsubsection{Characteristics of a good performance metric}

A number of studies in the literature discuss the required characteristics for a metric to be valuable and practical $[29,32,33]$. Hereunder, the most pertinent characteristics of a good metric are presented and discussed in relation to building performance. A performance metric should be:

a Fit-for-purpose. A good performance metric embodies the purpose or requirement of the investigation. It is designed to quantify a goal and to optimize the building design or operation to reach such goal.

b Reproducible. A good performance metric gives reproducible results when simulated and/or measured under similar scenarios and conditions (e.g., climate, type of occupants, etc.). 
c Easy to obtain. A good performance metric can be readily calculated by building measurements and/or simulation results, which should in turn be simple to collect.

d Comparable. A good performance metric enables comparison of results to other buildings to facilitate benchmarking and otherwise understanding relative performance.

e Quantitative. A good performance metric is quantitative. A quantitative benchmark is the starting point to improve a building's performance. "If you cannot measure it, you cannot improve it" (cit. Lord Kelvin).

f Accessible. A good performance metric is straightforward and should not be based on complicated indexes that users (architects, consultants, building engineers, etc.) do not know how to interpret or influence. This aspect is particularly relevant in the design process of a building, as stakeholders with different expertise are involved.

g Actionable. A good performance metric presents information that allows the user to take action (e.g., what should be done?).

$h$ Unbiased. A good performance metric offers a neutral indication of a building's performance and does not intentionally or unintentionally mislead metric users. This aspect is particularly sensitive to the normalization factor, and strongly relates to comparable.

Ensuring that all these characteristics are met simultaneously is a challenging task and it may not always be possible. A valid performance metric should not necessarily incorporate all these criteria. Instead, all these criteria should be considered and discussed while proposing and developing a novel performance metric. Augenbroe [34] argues that, while designers certainly try to fulfill the client's performance requirements, the lack of a proper framework that defines measures and measurement methods will inevitably cause a communication gap between demand (client) and supply (design engineering service providers).

In summary, when developing a building performance metric, it is important to: i) clearly define its pertinent high-level performance objective, ii) consider and detail the conceptual, spatial and temporal hierarchy, iii) clarify for which phases in the building lifecycle the metric is appropriate and can be obtained, and iv) how it can be obtained. The key characteristics of a good performance metric (i.e., fit-for-purpose, reproducible, easy to obtain, comparable, quantitative, accessible, actionable, and unbiased) ought to be discussed.

\section{Occupant-centric methods: examples}

Generally speaking, occupant-centric building performance metrics related to energy use can belong to three categories: (i) metrics related to occupancy and occupant normalization, (ii) metrics related to non-adaptive occupant actions, and (iii) metrics related to adaptive occupant actions. To demonstrate the importance of occupant-centric building performance metrics to complement conventional building performance metrics, these three domains are explored using rich illustrative datasets that were available to the authors. Once each metric is developed and demonstrated using measured and/or simulated data, the metrics are evaluated with regards to the approach laid out in the previous section.

\subsection{Occupant density and energy normalization schemes}

Two occupant-centric metrics pertaining to occupant density and utilization of buildings were explored. The first metric is related to energy and GHG emission normalization by number of occupants rather than floor area. The second metric examines building utilization to establish feasibility of hoteling-style office management and probabilistic heat gains from occupants.

\subsubsection{Energy and GHG emission normalization by occupancy}

As an illustrative example of the impact of normalization, consider the Canadian residential building stock. In Canada, energy efficiency of homes has significantly improved if energy use is normalized by floor area. Between 1990 and 2013, the energy use intensity has decreased by $35 \%$ [35]. During the same time, GHG emission intensity, also normalized by housing stock floor area decreased by about $44 \%$ (Fig. 3). Note that this decrease is a result of both decreasing energy use intensity and decreasing GHG emission intensity of the energy supply (the latter effect is responsible for one-fourth of the total reduction) [35].

However, during this same period, floor area per person for the housing stock increased by $28 \%$, as shown in Fig. 4 [36].

Thus, the increasing floor area significantly offsets the gains in energy efficiency and reduction in GHG intensity of energy supply. The net effect, now normalized by population, shows only a decrease of $18 \%$ and $29 \%$ for energy and GHG emissions, respectively (Fig. 5).

Table 1 provides a subjective evaluation of the current metrics' ability to meet the aforementioned metric criteria.

\subsubsection{Building utilization}

To investigate and quantify probabilistic occupancy for various operational and design applications, this section explores several such metrics and applies them to a dataset from occupancy in $\mathbf{4 6}$ private offices. Using detailed occupancy data, we can determine building utilization and the potential for improvement in utilization for current and future buildings with similar usage patterns. We propose four specific metrics to quantify hoteling potential (HP) in office buildings:

- Minimum ratio of required number of workstations to number of employees if employees relocate on a daily basis for 95 and $99 \%$ of days, $H P_{\text {daily,95 }}$ and $H P_{\text {daily, }, 99}$. That is, $5 \%$ or $1 \%$ of the year, there would be insufficient workstations if this ratio of workstations to employees were provided.

- Minimum ratio of required number of workstations to number employees if employees relocate on a weekly basis for 95 and $99 \%$ of days, $H P_{\text {weekly,95 }}$ and $H P_{\text {weekly,99. These values will tend to }}$ be higher than those for the daily relocations because a workstation is considered occupied for the week if an occupant uses it just once during that week.

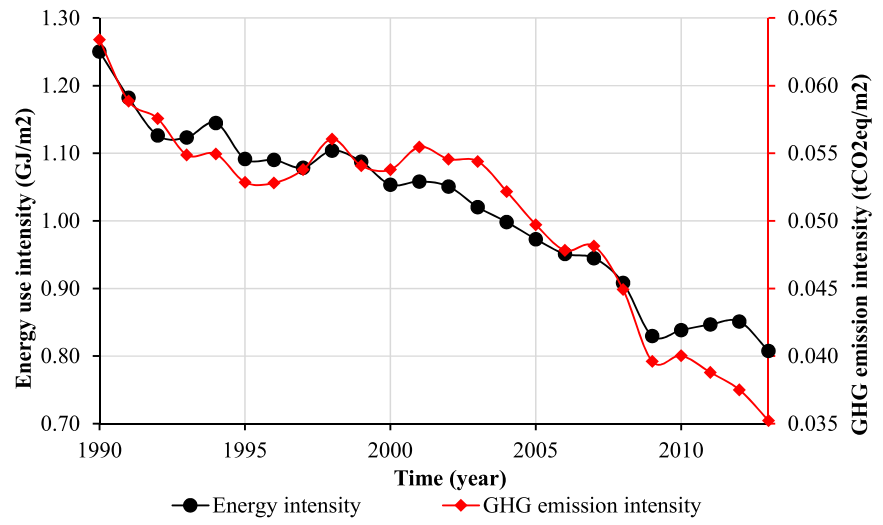

Fig. 3. Energy use and GHG emission intensity, normalized by floor area, for Canada's detached housing stock between 1990 and 2013 [35]. 


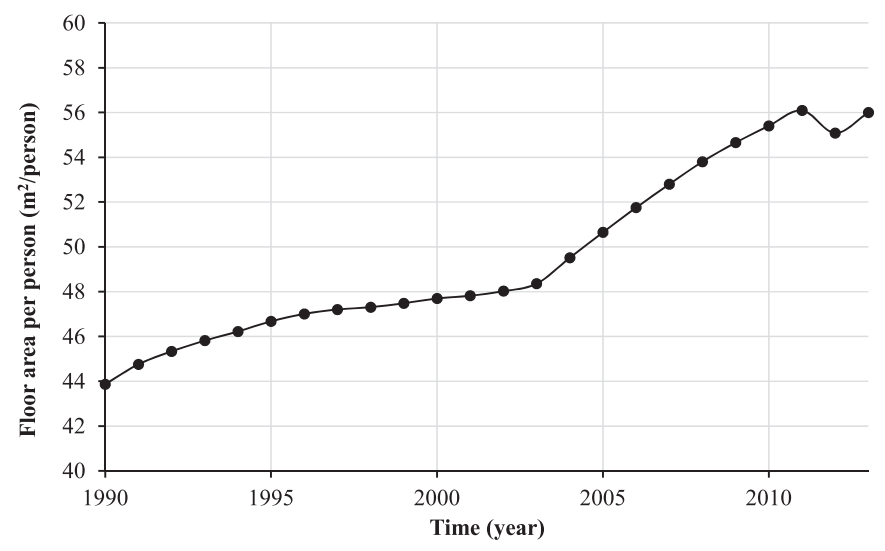

Fig. 4. Housing floor area per person in Canada between 1990 and 2013 [36].

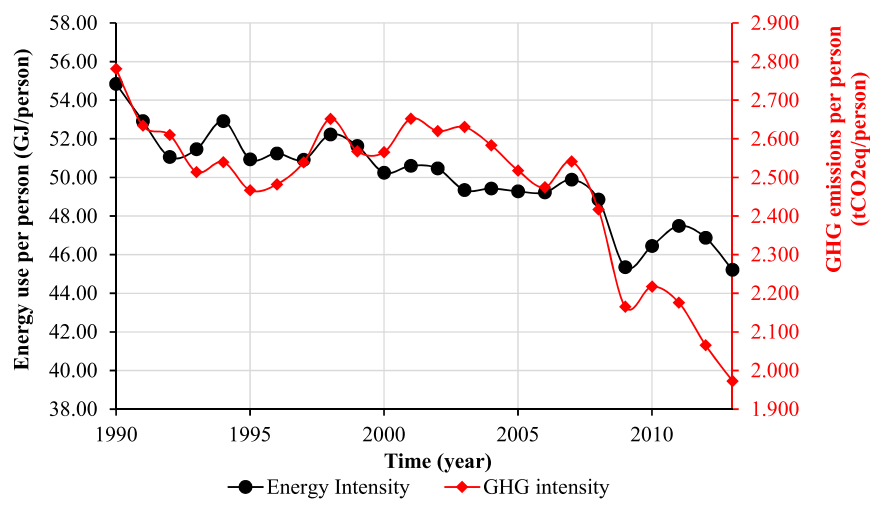

Fig. 5. Energy use and GHG emissions normalized by population.

These metrics provide a method to property owners or managers to take calculated risks about the number of workstations they must supply to ensure that they do not meet the demand for workspaces during just 1 or $5 \%$ of days or weeks. The inverse value of the HP metrics indicates the allowable increase in number of employees possible for the current number of workstations.

Typically, risk in buildings that employ hoteling-style office management is then further mitigated through online systems that prevent employees from accidentally arriving to a building that is at full occupancy. Overflow rooms (e.g., internal cafes or reconfigurable meeting rooms) can also be used.
Along the same vein of reasoning, another metric deals with probabilistic building utilization for the purpose of assessing cooling loads and ventilation rates for equipment sizing. Following the approach for climatic design conditions, which use $99.0^{\text {th }}$ and $99.6^{\text {th }}$ percentile design conditions (ASHRAE 2013), the sample principle can be applied to $99.0^{\text {th }}$ and $99.6^{\text {th }}$ percentile occupancy. We hereby define two probabilistic occupancy metrics as:

- The number of occupants at representing the $99.0^{\text {th }}$ percentile for a given population, OCC $_{99.0}$. This is, only $1 \%$ of the time are there more than ${ } C C_{99.0}$ occupants present.

- The number of occupants at $99.6 \%$ of maximum annual (or sample) occupancy, OCC $_{99.6}$.

Notably, these metrics are calculated much like the hoteling potential metrics, except the 5-min dataset was used. Their values can either be derived from simulation or measurement in real buildings. OCC $_{99.0}$ and ${ }^{O C C_{99.6}}$ are primarily targeted at the design stage with the hopes to reduce equipment (e.g., HVAC and toilets) sizing and tuning of operating HVAC systems (e.g., outdoor air volume flow schedules).

Other types of buildings could have different metric definitions (e.g., cafes could have hourly relocations, university libraries may have 4-h relocations, and hospital beds' relocation frequency would depend greatly on the severity of patient conditions). In general, the absolute definitions of these metrics is not critical. Instead, they should be defined for the specific context at hand. In structural engineering applications, designs must survive very rare events (e.g., 100-year flood). In a café, occupancy at $100 \%$ occupancy is relatively inconsequential compared to office worker productivity loss associated with not having space to work. Similarly, in economic terms, the event of an office worker who loses time because the building is overcapacity is likely more severe than an HVAC system that momentarily cannot quite keep up with cooling loads due to its slight undercapacity.

To provide a concrete example, a year-long dataset (including weekends and holidays) from 46 private offices containing either professors or administrators at Carleton University in Ottawa, Canada was explored. The occupancy sensor event-based data were obtained from wall-mounted passive infrared (PIR) sensors and converted to 5-min timestep data. Occupancy state was considered true for any occupant detections during each 5-min period. However, single 5-min or less occupancy events surrounded by ten or more minutes of vacancy before and after were considered janitorial visits.

The distribution of the number of simultaneously occupied

Table 1

Assessment of the occupant normalization metrics (energy use and GHG emissions per person) as per the criteria.

\begin{tabular}{|c|c|}
\hline Criteria & Evaluation \\
\hline $\begin{array}{l}\text { Fit-for- } \\
\text { purpose }\end{array}$ & $\begin{array}{l}\text { This metric allows energy consumption or GHG emissions to be quantified on the basis of designed and measured building utilization (quantified as number } \\
\text { of people who regularly occupy it). }\end{array}$ \\
\hline Reproducible & The results of energy and GHG emissions normalization by person is dependent on consistent measurement and definition of the inputs. \\
\hline $\begin{array}{l}\text { Easy to } \\
\text { obtain }\end{array}$ & $\begin{array}{l}\text { The downside of normalizing energy and GHG emissions by number of occupants is that this normalization factor can be difficult to quantify. In the current } \\
\text { example, the population of Canada was used. But at smaller scales, one must not only count the number of occupants but also decide what constitutes an } \\
\text { occupant (e.g., if an individual splits their time between two homes). Further issues may arise for seasonal occupancy patterns and occasional/casual } \\
\text { occupants, whereby some occupants may be counted more than once or not at all. }\end{array}$ \\
\hline Comparable & $\begin{array}{l}\text { This metric is aimed at comparing similar buildings, but should not be used across different building types (e.g., hospitals are likely to have much higher } \\
\text { energy use per occupant than homes). }\end{array}$ \\
\hline Quantitative & $\begin{array}{l}\text { This metric requires meters and sensors for existing buildings. Quantification during simulation-aided design is much more straightforward because metric } \\
\text { inputs are readily available, though not necessarily accurately known. }\end{array}$ \\
\hline Accessible & Energy normalization by person is likely intuitive to all stakeholders. Any ambiguity arises from the definition of the inputs. \\
\hline Actionable & $\begin{array}{l}\text { Energy normalization by person reveals two possible solutions - (1) improve energy efficiency, and (2) improve building utilization. In contrast, energy use } \\
\text { intensity by floor area only points to the former solution. }\end{array}$ \\
\hline Unbiased & Energy normalization by person significantly reduces the bias of EUI because buildings with low occupant density are not unfairly favored. \\
\hline
\end{tabular}


offices out of 46 was tabulated and is shown in Fig. 6. This graph indicates the cumulative probability distribution for the number of simultaneously present occupants at various frequencies from every $5 \mathrm{~min}$ to monthly. To help the reader interpret the figure, consider these interpretations:

- The daily frequency curve indicates the cumulative probability of having at least some given number of occupants at least once during the day (even for a 5-min period). For instance, there is a $50 \%$ chance that there will be 30 or fewer occupants present on a given day (within the one-year sample). Meanwhile, there is about a $99 \%$ chance that there will be 42 of fewer occupants, out of the possible 46, on any given day (this is the approach required to compute $H P_{\text {daily,99). Put differently, an employer }}$ faces about a $1 \%$ chance that providing 42 workstations to 46 employees would be insufficient on any given day.

- The 5-min frequency curve indicates the cumulative probability of having at least some given number of occupants at least once during a 5-min timestep. This curve only exceeds zero above approximately $60 \%$, indicating that $60 \%$ of the 5 -min timesteps have zero occupants. This is largely explained by the fact that all timesteps were considered in the analysis and thus many of them occur at night and during weekends and holidays. Fig. $6 \mathrm{~b}$ indicates that there is a $99.0 \%$ probability of having 17 or fewer occupants for a given 5-min timestep (i.e. where the 5-min curve intersects the $99.0 \%$ cumulative probability threshold). It should be noted that a limitation of the current dataset is that occupants' absence from an office does not necessarily mean they are not in the building, which has implications on direct application to whole-building cooling load calculations. It should also be noted that a similar approach to the current one could be taken with the weekends, holidays, and nights filtered out.

- The monthly frequency curve defines the probability of finding a given number of occupants in their offices at any given time during the month. This curve has a distinctly different shape than the higher frequency curves because it is highly likely that an occupant will at least make a single appearance during a given month. The authors acknowledge that there is a possibility that cleaning, maintenance, or administrative staff caused a brief detected occupancy (though we attempted to remove these events, as explained previously).
Based on the example above, the corresponding metric values are summarized in Table 2 . The high values for $H P_{\text {weekly }}$ indicate that all 46 occupants were present at some time during more than $5 \%$ of weeks. Thus if hoteling-style office management were implemented for these 46 offices, the relocation frequency should be higher than weekly (e.g., daily).

The fact that peak simultaneous occupancy (5-min timestep) is much lower than full capacity corroborates similar studies (e.g., [38]), which found the commonly-used ASHRAE Standard 90.1's [12] peak diversity factor of $95 \%$ to overestimate real observations. Table 3 provides a subjective evaluation of the hoteling potential and building utilization metrics' ability to meet the aforementioned metric criteria.

\subsection{Non-adaptive behavior: plug loads}

Plug loads are among the most significant energy end uses in buildings - particularly office buildings. Yet, they are typically represented by energy use intensity or power density (e.g., expressed in $\mathrm{kWh} /\left(\mathrm{m}^{2} \mathrm{a}\right)$ and $\mathrm{W} / \mathrm{m}^{2}$, respectively) and very basic schedules. This section proposes several metrics to better acknowledge habits of occupants and utilization of buildings. The following metrics are explored:

- Office equipment energy use during occupied periods, $E_{o c c}$,

- Office equipment energy use during vacant periods, $E_{v a c}$,

- Ratio of office equipment energy during occupied periods to total office equipment energy, $R_{\text {plug }}$.

In the examples that follow, the energy terms are normalized in several different ways on the basis of data availability.

Table 2

Summary of probabilistic occupancy metric results for sample data.

\begin{tabular}{lll}
\hline Metric & Percent of 46 offices & Absolute value (based on 46 offices) \\
\hline HP $_{\text {daily }, 95}$ & $87 \%$ & 40 \\
HP $_{\text {daily,99 }}$ & $91 \%$ & 42 \\
HP $_{\text {weekly }, 95}$ & $100 \%$ & 46 \\
HP $_{\text {weekly,99 }}$ & $100 \%$ & 46 \\
OCC $_{99}$ & $37 \%$ & 17 \\
OCC $_{99.6}$ & $41 \%$ & 19 \\
\hline
\end{tabular}

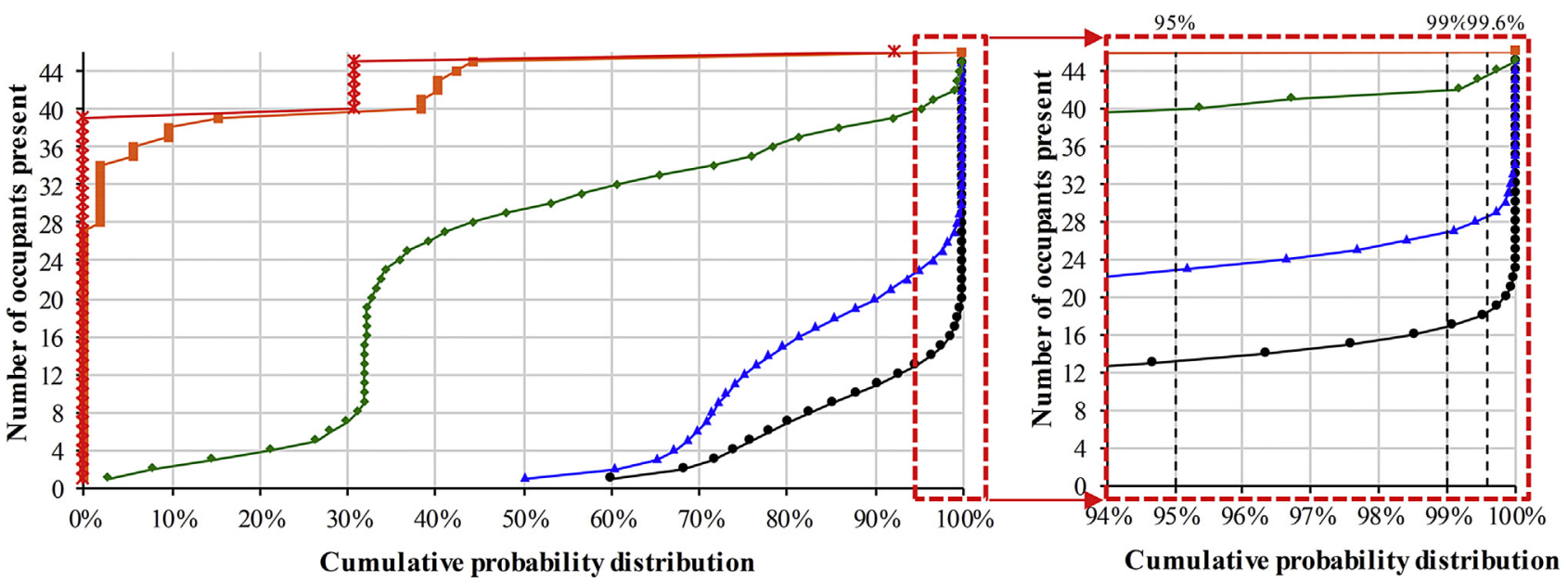

$\multimap 5$ minutes $\longrightarrow$ hour $\longrightarrow$ day $\longrightarrow$ week $\rightarrow$ month

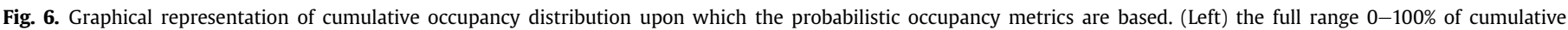
probability is shown; (Right) Only the top $94 \%$ of cumulative probability is magnified. 
Table 3

Assessment of the probabilistic occupancy metrics as per the criteria.

\begin{tabular}{|c|c|}
\hline Criteria & Evaluation \\
\hline $\begin{array}{l}\text { Fit-for- } \\
\text { purpose }\end{array}$ & $\begin{array}{l}\text { This set of metrics provides an indication of actual building utilization by occupants and can be applied throughout the building life-cycle if adequate data } \\
\text { are available. For existing buildings, these metrics can be used for operations or to support decisions to downsize or increase building floor area. For } \\
\text { simulation, this metric is primarily applicable if detailed occupancy models are used; not simple diversity schedules. }\end{array}$ \\
\hline Reproducible & $\begin{array}{l}\text { These metrics are reproducible from measurements as long as the occupancy data is reliable. If stochastic occupancy models are used in simulation, each } \\
\text { simulation run may lead to different results. However, use of larger sample sizes (durations, number of occupants) and/or Monte Carlo simulations can } \\
\text { provide greater definition of uncertainty. }\end{array}$ \\
\hline $\begin{array}{l}\text { Easy to } \\
\text { obtain }\end{array}$ & $\begin{array}{l}\text { Computation of these metrics is relatively straightforward with some basic knowledge of scripting and probability, whether the data are obtained from } \\
\text { simulation or existing buildings. In existing buildings, there are numerous available and emerging methods to obtain detailed occupancy data [21,39]. } \\
\text { Importantly, the hoteling metric requires occupants to be distinguishable; otherwise, we cannot distinguish, for example, if one occupant is present just in } \\
\text { the morning and a second just in the afternoon from an occupant who is present all day. In the current example, the authors had the privilege of private } \\
\text { office data whereby PIR sensors indicated presence of individual occupants. }\end{array}$ \\
\hline Comparable & $\begin{array}{l}\text { These metrics can be directly compared for different buildings or time periods in the same building, though values are expected to vary significantly for } \\
\text { different building types. Moreover, the ideal hoteling potential relocation frequency may be reduced or extended depending on activity and building type } \\
\text { (e.g., café, library, laboratory). }\end{array}$ \\
\hline Quantitative & These metrics are quantitative, but require occupancy sensors for operating buildings. \\
\hline Accessible & $\begin{array}{l}\text { These occupant utilization metrics can be presented in graphical form (e.g., Fig. 7) or as 'snapshots' at standardized values (e.g., } H P_{\text {daily,95). Some basic }} \\
\text { understanding of statistics and cumulative distributions is required. }\end{array}$ \\
\hline Actionable & $\begin{array}{l}\text { These metrics are aimed at two actions: (1) reducing floor area or the need to build more buildings by increasing occupant density and space utilization and } \\
\text { (2) reducing equipment sizing based on statistics of occupant utilization. Moreover, the metrics could be used to improve the hoteling scheduling systems } \\
\text { (i.e., to shift timing of occupancy and to smoothen periods of peak occupancy). }\end{array}$ \\
\hline \multirow[t]{2}{*}{ Unbiased } & $\begin{array}{l}\text { These metrics present data in an aggregated form and have minimal bias. Perhaps one exception to this is that, since all timesteps were included in the } \\
\text { analysis represented in Fig. 7, the timestep and hourly curves could be interpreted as: all offices are vacant for more than half the time. This is true, but in the } \\
\text { context that offices are generally vacant at night and weekends. }\end{array}$ \\
\hline & $\begin{array}{l}\text { The underlying data from which probabilistic metrics are generated could also be biased. The current data set includes both teaching and summer terms and } \\
\text { is thought to be representative. But ideally, data would be collected for no less than one year to remove the bias from seasonal variations. }\end{array}$ \\
\hline
\end{tabular}

\subsubsection{Office-level plug loads}

To examine typical office plug loads, a year's worth of highresolution plug load data and corresponding occupancy data was examined for 10 private offices in Ottawa, Canada with floor areas of $15 \mathrm{~m}^{2}$ [40]. As previously noted in this paper, these metrics can be quantified because of advances in occupancy sensing capabilities and a trend towards electricity metering with higher spatial and temporal resolution. The current approach provides even greater information as it accounts for workday durations, absences, and intermediate breaks. These offices each have a passive infrared (PIR) sensor to detect occupancy and are a subset of the 46 in the previous example. To add context to the calculated metrics, they were also calculated from the standard Department of Energy (DOE) Reference Building schedules [41] on the basis of the plug load and occupancy schedules and a nominal plug load density of $10.76 \mathrm{~W} / \mathrm{m}^{2}$ (each of the 10 measured offices has a floor area of $\left.15 \mathrm{~m}^{2}\right)$.

The results in Fig. 7 show that 9 of the 10 offices (all offices but Office 2 ) have an $R_{\text {plug }}$ of $65 \%$ or more. This ratio is significantly higher than calculated from the DOE schedules, though this is largely because the measured office occupancy was significantly below the DOE schedule ( $1.85 \mathrm{~h}$ per weekday versus $10.2 \mathrm{~h}$ per weekday, on average). However, this ratio suggests a high level of potentially wasted energy. Though a survey of office workers suggests that about half of occupants intentionally leave computers on overnight for the sake of a remote desktop connection or for syncing data to a cloud server [40]. The mean monthly energy of the 10 offices is about two-thirds as much as DOE. The measured data show high inter-occupant variability; the highest energy user consumed 44 times more than the lowest energy user during the year-long measurement period.

\subsubsection{Suite-level office plug loads}

To illustrate these metrics at a more typical metering scale - the office suite level - data from 14 floors, each with an area of 2000 $\mathrm{m}^{2}$, of an office tower in Ottawa, Canada was examined. The tenants primarily consist of accounting, legal, and engineering firms. While several tenants have large servers, these electric loads were

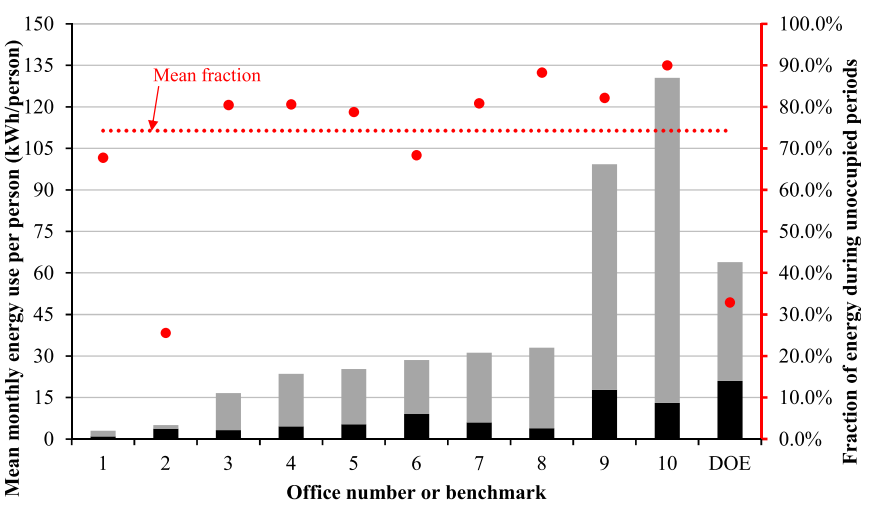

Monthly vacant energy use for each occupant (Evac/person)

- Monthly occupied energy use for each occupant (Eocc/person)

- Fraction of energy during vacant periods, Rplug

Fig. 7. Monthly plug load energy per person versus occupancy data for 10 private offices compared to DOE estimates based on ASHRAE 90.1 schedules for large offices.

submetered separately and are excluded from the current analysis. However, small servers (with a continuous electric power consumption) are not excluded. Several of the floors have multiple tenants, but the majority of tenants occupy entire floors or several floors. For these data, the measured energy includes all plug load electricity and excludes other electricity end uses such as lighting and HVAC.

Because concurrent occupancy data was not directly available, the hourly energy profile obtained for each suite was used as a proxy for occupancy. Specifically, daily occupancy was estimated to commence at the time when the time derivative of the plug load profile was greatest and end when it was the lowest. The DOE schedule, provided again for context, was treated the same way for consistency. Contrary to the single office example, for the suitelevel metering, a suite was considered to be occupied if at least one occupant was detected. These assumptions lead to some bias and potentially underestimate the value of $R_{\text {plug. That is, occupancy }}$ is unlikely to be at full capacity. Ultimately, this metric could be 
used more effectively if the occupancy data were more specific; however, it is still an improvement over traditional metrics in that it provides an indication of energy use from office equipment during unoccupied periods.

The results in Figure 8 indicate that, unlike private offices, the suites show a relatively consistent fraction of unoccupied plug load energy, $R_{\text {plug, }}$ mostly ranging 0.4 to 0.6 . However, despite the fact that most of these offices use a somewhat higher fraction of energy during unoccupied periods than indicated by the DOE schedule, they typically use less overall energy. The average tenant used 70\% less energy compared to the level that Deru et al. [41] suggest. Other researchers (e.g., [42]) have found typical assumptions and lease agreements on office equipment power densities to be generally much higher than measured. The diversifying effect of the current office plug load data, which spans tens to hundreds of occupants, resulted in the highest energy suite consuming only 2.2 times the amount of energy consumed by the lowest energy suite. Like for the private offices, these results reveal significant potential waste with regards to energy use during unoccupied periods. Table 4 provides a subjective evaluation of the developed plug loadrelated metrics' ability to meet the aforementioned metric criteria.

\subsection{Adaptive occupant behavior: lighting and daylighting}

In the past decade, so-called dynamic daylight metrics have become popularized through more advanced simulation capabilities and modelling standards (e.g., for LEED compliance) [11,31,43]. In contrast to previous metrics, such as daylight factor, dynamic daylight metrics account for annual performance, usually on a subhourly calculation basis. However dynamic daylight metrics typically evaluate the theoretical daylight availability or glare experienced by occupants in the building. But for energy-driven targets, impact of daylighting design on electric lighting use is of major interest. For many users of daylight autonomy (DA), there may be an implicit assumption that if there is adequate daylight that the lights can and will be off (either turned off by occupants or the daylight-controlled system). Recall that DA is the fraction of occupied time when daylighting contributes to sufficient workplane illuminance, as defined by some fixed threshold (e.g., 300 or $500 \mathrm{~lx}$ ) when the lights are not needed. However, actual lighting use is not necessarily tested by current metrics. For instance, it has been established that for private offices, manual-on/automatic-off lighting controls greatly outperform automatic-on/automatic-off $[8,44]$. Ease of access to adjustable building systems (e.g., window shades) also has significant impact on the occupants' propensity to

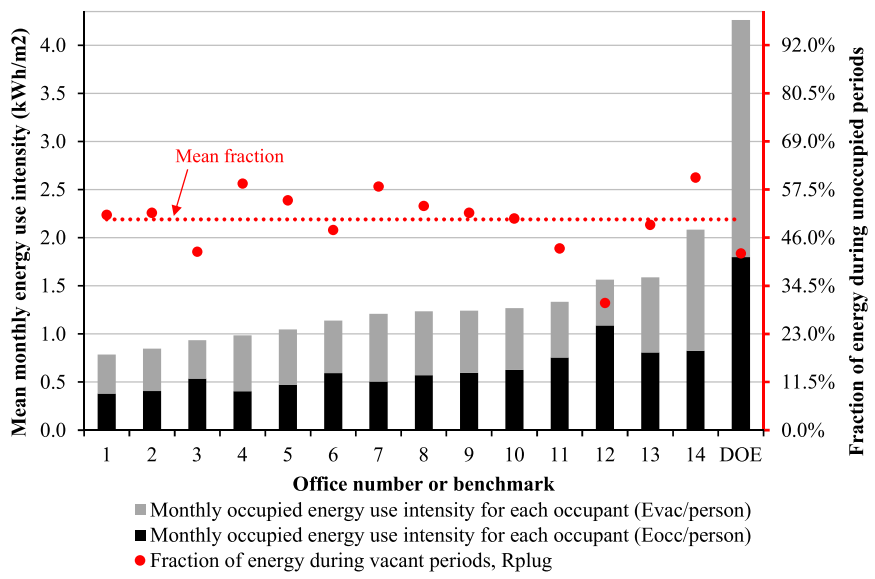

Fig. 8. Comparison of occupied and unoccupied plug load energy for 14 large office suites compared to DOE estimates based on ASHRAE Standard 90.1 schedules. use them [45]. It is also established that occupants do not control lights in consistent ways - both with regards to timing and with regards to illuminance level triggers [46,47].

In contrast to existing metrics, we propose a metric that simultaneously considers daylight availability, the lighting control scheme, and occupant behavior: the light utilization ratio (LUR):

$L U R=\frac{\text { time with lights on }}{\text { occupied time }}$

The total duration of measurement or simulation (e.g., months or years) is flexible but, like daylighting metrics, should ideally be a year to cover the annual climatic cycle. LUR may also apply to any size of space, though the example that follows is for private offices. Note that while LUR is related to DA, LUR can exceed 1.0 because the lights may be on before or after an occupied period. LUR cannot take on values below 0 and could theoretically take on the value infinity if the lights were on in a permanently unoccupied space.

To demonstrate the use of LUR in simulation applications, a $3 \mathrm{~m}$ wide by $3 \mathrm{~m}$ high by $5 \mathrm{~m}$ deep shoebox single-occupant office model in Ottawa, Canada was modeled in EnergyPlus v.8.6. The office model is south-facing with a $40 \%$ window-to-wall area ratio. Several different automated and manual lighting control schemes were compared, as summarized in Table 5. Control Scheme 4 in Table 5 represents the ideal controls associated with calculating DA. In reality, it is likely an undesirable control scheme because of the potential for frequent incorrect light switch-off events and misalignment of standard illuminance thresholds and personal daylight preferences [48].

Page et al.'s [49] stochastic occupancy model was used for occupancy because it includes intermediate absences (e.g., coffee breaks and brief meetings), though the DOE occupancy schedule for large office buildings [41] was used as an input for the occupancy model. Modelling intermediate absences is particularly important for assessing lighting energy since lights may not be turned off upon departure (or may have a substantial delay period programmed if automatically controlled). The Haldi and Robinson [50] stochastic window blind model was used to add some realism to the office.

Details of the implementation of stochastic occupant models can be found in Gunay et al. [51]. Because of the stochastic nature of these simulations, 100 simulations were run to obtain mean values. This number was confirmed to be conservative by Gunay et al. [51].

For the last lighting control scheme in Table 5, the calculated LUR $(0.404 \pm 0.006)$ plus DA equals 1 (i.e., the simulated DA for this office is about $60 \%$ ) because the last light control scheme corresponds to the standard assumptions made to quantify DA. For other lighting controls schemes two interesting conflicting phenomena are at play. First, if light switch-on actions are manual, the typical observed threshold is often lower than that used for DA (e.g., 300 or 500 lux). For instance, Reinhart and Voss [46] found that the mean workplane illuminance at which occupants turned on the lights was about 30-280 lux, depending on the occupant. Second, lights are unlikely to be turned off immediately after departure (as DA implicitly assumes). In reality, manual switch-off events are imperfect and even vacancy-controlled lighting typically uses a delay period of 15-30 min to prevent lights from turning off instantaneously if a present occupant become motionless. For instance, an occupant who spends $5 \mathrm{~h}$ in an office, departs four times for at least 15 min during the day, and has occupancy-on and vacancy-off (15-min delay), would use $20 \%$ more lighting energy than if there were no delay period.

If occupancy and light state data in an existing building are available, LUR can be computed quite easily. Using eight westfacing offices in Ottawa (a subset of the 46 offices investigated in 
Table 4

Assessment of the occupancy-based plug load metrics $\left(E_{v a c}, E_{o c c}\right.$, and $\left.R_{\text {plug }}\right)$ as per the criteria.

\begin{tabular}{|c|c|}
\hline Criteria & Evaluation \\
\hline $\begin{array}{l}\text { Fit-for- } \\
\text { purpose }\end{array}$ & $\begin{array}{l}\text { This set of metrics provides an indication of office equipment plug loads, with emphasis on identifying potentially wasted electricity during unoccupied } \\
\text { periods. It is less suitable for applying to simulation, where the likely input is based on standard schedules over which the designer has little control. }\end{array}$ \\
\hline Reproducible & These metrics are reproducible, but require separate metering and ideally occupancy sensing for quantification during building operation. \\
\hline $\begin{array}{l}\text { Easy to } \\
\text { obtain }\end{array}$ & $\begin{array}{l}\text { The ability to compute these metrics is dependent on the appropriate sensors and meters to detect occupants and measure energy use. As illustrated by the } \\
\text { relatively data-rich examples, some approximations had to be made about occupancy. }\end{array}$ \\
\hline Comparable & These metrics can be directly compared for different buildings (or smaller scales, depending on metering resolution). \\
\hline Quantitative & $\begin{array}{l}\text { These metrics are quantitative, but rely on electricy meters (with plug loads separated) and ideally occupancy sensors for operating buildings. } \\
\text { Quantification during simulation-aided design is much more straightforward because metric inputs are readily available. }\end{array}$ \\
\hline Accessible & These metrics are straightforward and related to existing metrics, with the exception of separating occupied and unoccupied loads. \\
\hline Actionable & These metrics are aimed at quantifying potential inefficiency of plug loads during unoccupied periods. \\
\hline Unbiased & $\begin{array}{l}\text { These metrics have low potential for bias in that they neglect the fact that some equipment may be required during unoccupied periods. For instance, some } \\
\text { employees may use desktop computers for simulation or remote access and small refrigerators operate throughout the day. }\end{array}$ \\
\hline
\end{tabular}

Table 5

Summary of LUR simulation results ( \pm values refer to the standard deviation of the results from the 100 runs).

\begin{tabular}{|c|c|c|c|}
\hline \# & Light-on control scheme & Light-off control scheme & LUR \\
\hline 1 & Occupancy-on & Vacancy-off with 15-min delay & $1.09 \pm 0.008$ \\
\hline 2 & Manual-on & Vacancy-off with 15-min delay & $0.141 \pm 0.013$ \\
\hline 3 & Manual-on & Manual-off & $0.234 \pm 0.019$ \\
\hline 4 & Occupancy-on AND workplane illuminance from daylight $<500$ lux & Vacancy-off without delay OR daylight-off if $\mathrm{E}_{\mathrm{wp}} \geq 500$ lux & $0.404 \pm 0.006$ \\
\hline
\end{tabular}

Section 4.1.2), lighting and occupancy data were assessed for the entire year of 2014. These private offices have lighting controls that are integrated into the building automation system such that occupants can manually turn on the lights and then there is a 30-min delay period between when the last occupancy event is recorded and when the lights are turned off. Notably, one of the occupants (referred to as Room number 3 in Table 6) complained that the lights were turning off too frequently when the delay period was $15 \mathrm{~min}$, prior to 2014. After the change to $30 \mathrm{~min}$ delay periods for all offices, complaints ceased. The interior of the geometricallyidentical offices is shown in Fig. 9.

Table 6 summarizes the annual results for the eight offices. Some interesting observations can be made from the LUR results. First, they vary significantly between each other considering that the offices are geometrically and functionally identical. Secondly, the LUR values are generally significantly higher than the simulation results might have suggested (the controls resemble Scheme 2 in Table 5). Lastly, one of the occupants' LUR values greatly exceeds a value of one. The underlying reason for the last two points is that a delay period of $30 \mathrm{~min}$ is highly adverse for occupants who routinely leave their offices to attend meetings, lectures, meals and coffee breaks. Thus, a significant amount of the time that the lights are on is during unoccupied periods. The considerable variation between occupants in all columns of Table 6 compared to the simulated results in Table 5 is that the first generation of stochastic occupant models (i.e., those that were used) tend to suppress interoccupant diversity [52]. The eight occupants' age, desk orientation, computer monitor orientation, and shade positions all vary. For

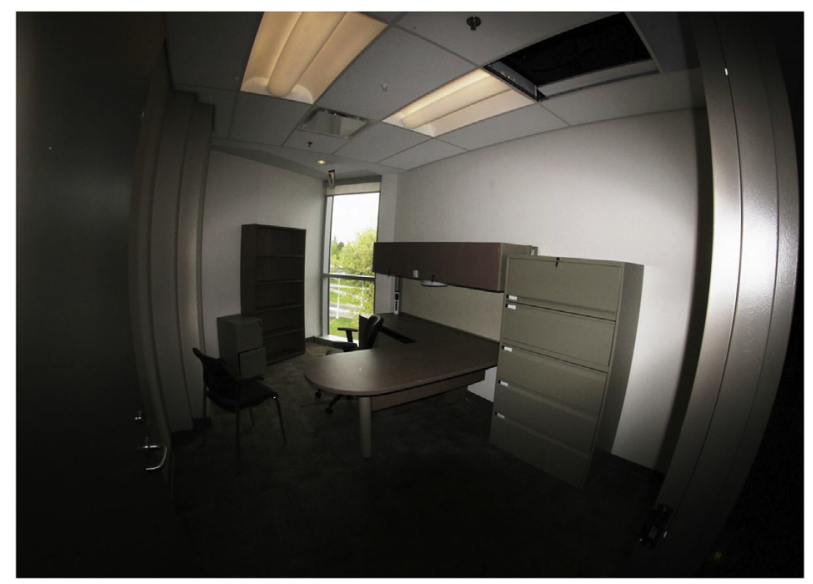

Fig. 9. Interior of Carleton University's Canal Building office. The window is directly west facing.

instance, the occupant in office number 3 leaves his shades closed most of the year. Notably, an occupant who primarily works at night would likely result in a high LUR value, though that is not the situation for these eight occupants. In general, this metric serves the purpose to identify possible anomalies or systemically high electric lighting use. But further investigation is needed to identify the root cause (e.g., nature of occupancy patterns, faulty controls

Table 6

Summary of measured occupancy, lighting use, and corresponding LUR for eight private offices in 2014.

\begin{tabular}{llll}
\hline Room number & Occupied period (hours) & Duration with lights on (hours) \\
\hline 1 & 153 & 63 & 111 \\
2 & 610 & 0.41 \\
3 & 786 & 0.18 \\
4 & 634 & 219 & 91 \\
5 & 519 & 3 & 0.35 \\
6 & 25 & 314 & 0.18 \\
7 & 341 & 403 & 0.13 \\
8 & 431 & 0.92 \\
\hline
\end{tabular}


logic, faulty sensor).

Since the time when DA was developed and then popularized by Reinhart et al. [31] several variations have been developed to consider dimmable lighting (continuous DA) and spatial effects (spatial DA) [43]. However, these have not specifically addressed interaction between occupants and lighting controls. Table 7 provides a subjective evaluation of lighting utilization ratio's ability to meet the aforementioned metric criteria.

\section{Discussion and conclusions}

This paper aimed at introducing a different point of view to assess buildings' energy performance, by focusing on the recipients of the services provided by the building, i.e., the occupants. It is argued that this type of research and approach has acquired meaning only in the last years, due to the diffusion of BACSs and occupancy sensing techniques. A literature review of the existing building performance metrics related to occupants highlighted how occupants are a central figure of comfort-related performance metrics, while they are barely considered in energy performance metrics.

The two key aspects that ought to be considered when proposing a metric are hierarchy and dynamism. As our objectives typically change throughout the building lifecycle, the appropriate metrics' hierarchy also changes. Assessing performance metrics throughout the building lifecycle is important for setting meaningful targets and ensuring they are achieved. Moreover, metrics are useful for diagnosing the causes of underperformance. A list of key criteria that should be taken into account when developing performance metrics was proposed. While some of these criteria can be easily assessed (e.g., quantitative), others need deeper consideration (e.g., easy to communicate and unbiased). The authors do not claim that a performance metric should embody all the key criteria, but rather that they should all be discussed and assessed.

The proposed approach was tested in Section 4, where the authors discussed a number of illustrative occupant-centric performance metrics. First, an example of normalization by number of occupants showed how adopting this metric might convey a more meaningful message than EUI regarding societal sustainability of the building stock. At a smaller scale, however, obtaining the number of people in a building could be harder than obtaining information about a building's floor area.

The authors hope that highlighting the benefits of looking at a building performance through the lens of occupants will inspire more and more designers to integrate occupancy sensing techniques in the early phases of a building design. Similarly to the issues emerged for the normalization per floor area, it is important to agree on the meaning of "number of occupants", be it - for example - full capacity, full-time equivalent, or occupants actually present.

A number of metrics were proposed to quantify the hoteling potential (HP) of buildings. These metrics could be very useful in the operation phase (e.g., to dedicate unused spaces to other destinations of use or to optimize the building's space conditioning). While it is expected that people would generally understand the single value (e.g., $H P_{\text {daily, } 95}=90 \%$ means that providing 9 workstations for every 10 employees is sufficient for $95 \%$ of days), the graphical representation (Fig. 6) is more informative but may be harder to understand.

We proposed the ratio of office equipment energy during occupied periods to total office equipment energy ( $\left.R_{\text {plug }}\right)$ to quantify potentially wasted equipment energy. This metric is actionable at different space resolutions (single office to whole building), and could reflect habits that cannot be easily modified, such as remote controlling of PCs. Rplug is still relevant to notify occupants and enable them to take informed choices about their energy consumption. Fig. 8 demonstrates how quantifying $R_{\text {plug }}$ for higher space resolutions (in this case, office suites) still provides information about the building, but leads to an averaging effect. The light utilization ratio (LUR) was proposed to easily quantify occupants' light operation. Unlike DA, which quantifies the theoretical degree to which daylight can displace electric lighting, LUR includes the impacts of daylight availability, occupancy patterns, occupants' use of light switches, and the impact of lighting control schemes. Moreover, the LUR supports identification of anomalies related to manual and automated light operation.

In summary, this paper represents a first rigorous attempt of introducing occupants in the traditional assessment of building performance. Proposing a novel approach to look at building performance proved to be a difficult task, especially when it comes to biased information. The approach introduced here is suitable to provide guidance for developing occupant-centric performance metrics. However, given the substantial novelty of the topic, this field is currently in the "discovery phase" [54], also referred to as "phase of divergent thought", in which all possible solutions are explored. We hope that this exercise will inspire further studies, but we expect that only a small number of occupant-centric performance metrics will reach maturity and will be integrated in the design process. Ultimately, for widespread use of occupant-centric building performance metrics to prevail, they will have to play a role in building codes and standards. Moreover, their automated

Table 7

Assessment of the lighting utilization ratio metric as per the criteria.

\begin{tabular}{|c|c|}
\hline Criteria & Evaluation \\
\hline $\begin{array}{l}\text { Fit-for- } \\
\quad \text { purpose }\end{array}$ & $\begin{array}{l}\text { LUR can be used through the building life-cycle and can be used to influence both daylighting design and lighting controls. Moreover, it could be used for } \\
\text { communicating lighting use to individual occupants. }\end{array}$ \\
\hline Reproducible & Due to the stochastic nature of some occupancy and light use models, numerous simulation runs are required to quantify uncertainty. \\
\hline $\begin{array}{l}\text { Easy to } \\
\text { obtain }\end{array}$ & $\begin{array}{l}\text { LUR can be estimated during design using simulation, as long as a light use behavior model and/or automated control scheme is available or implemented. } \\
\text { Like DA, LUR does still require daylight simulations. During the operational phase of a building, LUR can be determined as long as occupancy and light state } \\
\text { are measured. Lighting state is often more straightforward and cost-effective to measure than daylight illuminance because of the impracticality of } \\
\text { measuring illuminance at the workplane [53]. }\end{array}$ \\
\hline Comparable & $\begin{array}{l}\text { LUR is a single index that can be applied to any space, though context of building geometry, space uses, and lighting controls is important. Users of LUR may } \\
\text { wish to combine multiple spaces and normalize by floor area. }\end{array}$ \\
\hline Quantitative & LUR can be directly quantified from occupancy and light state time series data. \\
\hline Accessible & $\begin{array}{l}\text { LUR is a straightforward metric in principle; it is the underlying modelling assumptions that add complexity. However, LUR is not bound by } 0 \text { and } 1 \text {, as DA is; } \\
\text { this could lead to some confusion. Moreover, if LUR is computed from simulation, users are required to have an understanding of how occupant light use } \\
\text { models function; whereas DA is purely based on daylight potential (with inputs of geometry, surface finishes, and climate). }\end{array}$ \\
\hline Actionable & $\begin{array}{l}\text { Like DA, LUR is most practically used when comparing multiple designs or control schemes, rather than for the sake of the absolute value. However, values } \\
\text { of LUR above } 1 \text { could because for concern since they indicate lights are on longer than a space is occupied. }\end{array}$ \\
\hline Unbiased & LUR attempts to resolve the bias caused by neglecting the importance of lighting controls in architecture-oriented daylight metrics. \\
\hline
\end{tabular}


computation in BPS tools and BACSs will be critical. The few examples presented here highlight the potential for stressing the ultimate scope of buildings: efficiently provide comfort and safety for their occupants. Should it become common practice to evaluate buildings from an occupant-centric performance perspective, there will be an even stronger need for guidelines to appropriate occupant behavior modeling in building performance simulation [55].

\section{Acknowledgements}

This work originated and developed thanks to the excellent research networking provided by IEA EBC Annex 66 "Definition and Simulation of Occupant Behavior in Buildings". The data contributions from Burak Gunay, Sara Gilani, and Isis Bennet are gratefully acknowledged.

\section{References}

[1] T. Kesik, Vital Signs: towards Meaningful Building Performance Indicators, Toronto, Canada, 2015, http://dx.doi.org/10.13140/RG.2.1.3333.3606.

[2] IEA, Building Energy Performance Metrics: supporting Energy Efficiency Progress in Major Economies, 2015.

[3] U.S. Department of Energy (DOE), Buildings Performance Metrics Terminology, 2009. https://energy.gov/sites/prod/files/2013/12/f5/metrics_ terminology_20090203.pdf.

[4] R.J. Hitchcock, High performance commercial building systems software interoperability for energy simulation, World Wide Web Internet And Web Inf. Syst. 51244 (2002)

[5] G.C. Foliente, R.H. Leicester, L. Pham, Development of the CIB Proactive Program on Performance Based Building Codes and Standards, Australia, 1998, http://cibworld.xs4all.nl/pebbu_dl/resources/literature/downloads/ 01General/07Foliente.pdf.

[6] A. Costa, M.M. Keane, J.I. Torrens, E. Corry, Building operation and energy performance: monitoring, analysis and optimisation toolkit, Appl. Energy 101 (2013) 310-316, http://dx.doi.org/10.1016/j.apenergy.2011.10.037.

[7] M.G.L.C. Loomans, A. Huovila, P. Lefebvre, J. Porkka, P. Huovila, J. Desmyter, et al., Key Performance Indicators for the Indoor Environment, 2011, pp. $1666-1675$.

[8] H.B. Gunay, W. O'Brien, I. Beausoleil-Morrison, S. Gilani, Development and implementation of an adaptive lighting and blinds control algorithm, Build. Environ. $113 \quad$ (2017) 185-199, http://dx.doi.org/10.1016/ j.buildenv.2016.08.027.

[9] The WELL Building Standard, Delos Living LLC, New York, NY, 2016.

[10] S. Carlucci, L. Pagliano, A review of indices for the long-term evaluation of the general thermal comfort conditions in buildings, Energy Build. 53 (2012) 194-205, http://dx.doi.org/10.1016/j.enbuild.2012.06.015.

[11] S. Carlucci, F. Causone, F. De Rosa, L. Pagliano, A review of indices for assessing visual comfort with a view to their use in optimization processes to support building integrated design, Renew. Sustain. Energy Rev. 47 (2015) 1016-1033, http://dx.doi.org/10.1016/j.rser.2015.03.062.

[12] ASHRAE, ANSI/ASHRAE/IESNA Standard 90.1-2013: Energy Standard for Buildings Except for Low-rise Residential Buildings, 2013.

[13] S. Carlucci, Thermal Comfort Assessment of Buildings, London, 2013.

[14] L. Schipper, R. Steiner, P. Duerr, F. An, S. Strom, Energy use in passenger transport in OECD countries: changes since 1970, Transportation 19 (1992) 25-42. http://link.springer.com/article/10.1007/BF01130772.

[15] J. Norman, H. MacLean, C. Kennedy, Comparing high and low residential density: life-cycle analysis of energy use and greenhouse gas emissions, J. Urban Plan. Dev. 132 (2006) 10-21.

[16] K. Ueno, Building energy performance metrics, Build. Sci. Dig. 152 (2010). https://buildingscience.com/documents/digests/bsd152-building-energyperformance-metrics.

[17] C. Warren, New working practice and office space density: a comparison of Australia and the UK, Facilities 21 (2003) 306-314.

[18] W.F. Cascio, Managing a virtual workplace, Acad. Manag. Exec. 14 (2000).

[19] N. Miller, Estimating Office Space per Worker, 2012. https://www.sandiego. edu/pipeline/documents/EstimatingOfficeSpaceRequirementsMay12012.pdf.

[20] B. Dong, K.P. Lam, Building energy and comfort management through occupant behaviour pattern detection based on a large-scale environmental sensor network, J. Build. Perform. Simul. 4 (2011) 359-369.

[21] H.B. Gunay, A.F. Fuller, W. O'Brien, I. Beausoleil-Morrison, Detecting occupants' presence in office spaces: a case study, in: eSim 2016, Hamilton, ON, 2016.

[22] O.T. Masoso, L.J. Grobler, The dark side of occupants\{|textquoteright $\}$ behaviour on building energy use, Energy Build. 42 (2010) 173-177.

[23] D. Harris, C. Higgins, Methodology for Reporting Commercial Office Plug Load Energy Use, 2013. https://newbuildings.org/wp-content/uploads/2015/11/ PlugLoadMetricsReportingGuide_CaseStudy1.pdf.
[24] C.A. Webber, J.A. Roberson, M.C. McWhinney, R.E. Brown, M.J. Pinckard J.F. Busch, After-hours power status of office equipment in the USA, Energy 31 (2006) 2487-2502, http://dx.doi.org/10.1016/j.energy.2005.11.007.

[25] C.F. Reinhart, O. Walkenhorst, Validation of dynamic RADIANCE-based daylight simulations for a test office with external blinds, Energy Build. 33 (2001) 683-697.

[26] R. Rezaee, J. Brown, G. Augenbroe, J. Kim, Assessment of uncertainty and confidence in building design exploration, Artificial Intelligence for Engineering Design, Analysis Manuf. 29 (2015) 429-441, http://dx.doi.org/ 10.1017/S0890060415000426.

[27] D.T.J. O'Sullivan, M.M. Keane, D. Kelliher, R.J. Hitchcock, Improving building operation by tracking performance metrics throughout the building lifecycle (BLC), Energy Build. 36 (2004) 1075-1090, http://dx.doi.org/10.1016/ j.enbuild.2004.03.003.

[28] T. Hong, S.C. Taylor-Lange, S. D'Oca, D. Yan, S.P. Corgnati, Advances in research and applications of energy-related occupant behavior in buildings, Energy Build. 116 (2016) 694-702, http://dx.doi.org/10.1016/j.enbuild.2015.11.052.

[29] M. Deru, P. Torcellini, Performance Metrics Research Project - Final Report, Golden, Colorado, 2005

[30] P.O. Fanger, Thermal comfort, Danish Technical Press, Copenhagen, Denmark 1970.

[31] C.F. Reinhart, J. Mardaljevic, Z. Rogers, Dynamic daylight performance metrics for sustainable building design, Leukos 3 (2006) 7-31.

[32] R.J. Hitchcock, M.A. Piette, S.E. Selkowitz, Performance Metrics and Life-cycle Information Management for Building Performance Assurance, in: Proceedings of the ACEEE '98 Summer Study on Energy Efficiency in Buildings, 1998.

[33] K.M. Fowler, A.E. Solana, K.L. Spees, Building Cost and Performance Metrics: Data Collection Protocol, 2005, http://dx.doi.org/10.2172/885473.

[34] G. Augenbroe, The role of simulation in performance based building, in J.L.M. Hensen, R. Lamberts (Eds.), Building Performance Simulation for Design and Operation, Spon Press, London/New York, 2011, p. 15.

[35] Natural Resources Canada (NRCan), Energy Use Data Handbook Tables: Residential Sector: Residential GHG Emissions by Energy Source and End Use, 2016.

[36] Natural Resources Canada (NRCan), Energy Use Data Handbook Tables: Residential Sector: Residential Housing Stock and Floor Space, 2016.

[38] P. Bouffaron, Revealing occupancy diversity factors in buildings using sensor data, in: Behavior, Energy and Climate Change Conference, Washington DC, USA, 2014, http://dx.doi.org/10.5811/westjem.2011.5.6700.

[39] K.P. Lam, M. Höynck, B. Dong, B. Andrews, Y.-S. Chiou, R. Zhang et al., Occupancy detection through an extensive environmental sensor network in an open-plan office building, in: IBPSA Building Simulation, 2009 pp. 1452-1459.

[40] H.B. Gunay, W. O'Brien, I. Beausoleil-Morrison, S. Gilani, Modeling plug-in equipment load patterns in private office spaces, Energy Build. 121 (2015) 234-249, http://dx.doi.org/10.1016/j.enbuild.2016.03.001.

[41] M. Deru, K. Field, D. Studer, K. Benne, B. Griffith, P. Torcellini, et al., U.S Department of Energy Commercial Reference Building Models of the National Building Stock, Publications (E), 2011, pp. 1-118 doi:NREL Report No. TP5500-46861.

[42] M. Sheppy, L. Gentile-Polese, S. Gould, Plug and Process Loads Capacity and Power Requirements Analysis: US Department of Energy, Energy Efficiency \& Renewable Energy, 2014.

[43] IESNA, LM-83-12 IES Spatial Daylight Autonomy (SDA) and Annual Sunlight Exposure (ASE), New York, New York, USA, 2012.

[44] A. Tzempelikos, The impact of manual light switching on lighting energy consumption for a typical office building, Int. High. Perform. Build. 9 (2010). http://docs.lib.purdue.edu/ihpbc/32.

[45] J. Day, J. Theodorson, K. den Wymelenberg, Understanding controls, behaviors and satisfaction in the daylit perimeter office: a daylight design case study, J. Interior Des. 37 (2012) 17-34.

[46] C. Reinhart, K. Voss, Monitoring manual control of electric lighting and blinds, Light. Res. Technol. 35 (2003) 243-260, http://dx.doi.org/10.1191 1365782803li064oa.

[47] A.D. Galasiu, J.A. Veitch, Occupant preferences and satisfaction with the luminous environment and control systems in daylit offices: a literature review, Energy Build. 38 (2006) 728-742.

[48] P. Boyce, Human Factors in Lighting, third ed., Taylor \& Francis, 2014.

[49] J. Page, D. Robinson, N. Morel, J.L. Scartezzini, A generalised stochastic model for the simulation of occupant presence, Energy Build. 40 (2008) 83-98 http://dx.doi.org/10.1016/j.enbuild.2007.01.018.

[50] F. Haldi, D. Robinson, Adaptive actions on shading devices in response to loca visual stimuli, J. Build. Perform. Simul. 3 (2010) 135-153, http://dx.doi.org/ 10.1080/19401490903580759.

[51] H.B. Gunay, W. O'Brien, I. Beausoleil-Morrison, Implementation and comparison of existing occupant behaviour models in EnergyPlus, J. Build. Perform. Simul. 9 (2016) 567-588, http://dx.doi.org/10.1080/19401493.2015.1102969.

[52] W. O'Brien, H.B. Gunay, F. Tahmasebi, A. Mahdavi, A preliminary study of representing the inter-occupant diversity in occupant modelling, J. Build. Perform. Simul. (2016) 1-18.

[53] S. Gilani, W. O'Brien, Review of current methods, opportunities, and challenges for in-situ monitoring to support occupant modelling in office spaces, 
J. Build. Perform. Simul. (2016) 1-18.

[54] A Study of the Design Process, Design Council, London, UK, 2005. http://www. designcouncil.org.uk.

[55] I. Gaetani, P.-J. Hoes, J.L.M. Hensen, Occupant behavior in building energy simulation: towards a fit-for-purpose modeling strategy, Energy Build. 121
(2016) 188-204. http://dx.doi.org/10.1016/j.enbuild.2016.03.038.

[56] W. Kampel, S. Carlucci, B. Aas, A. Bruland, A proposal of energy performance indicators for a reliable benchmark of swimming facilities, Energy Build. 129 (2016) 186-198. 